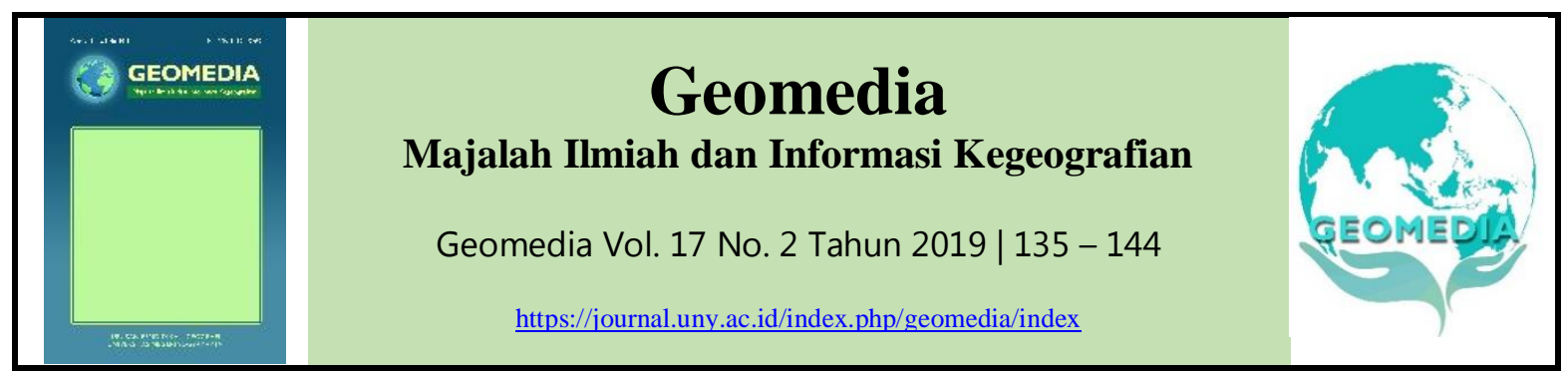

\title{
Analisis Potensi Lahan Pertanian Pangan Berkelanjutan Di Kabupaten Lamongan Tahun 2018
}

\section{Mitha Asyita Rahmawaty*}

Program Studi Diploma Empat (DIV) Penataan Ruang Dan Pertanahan, Sekolah Vokasi, Universitas Diponegoro,

Semarang, Indonesia

ashitamitha@gmail.com

*korespondensi penulis

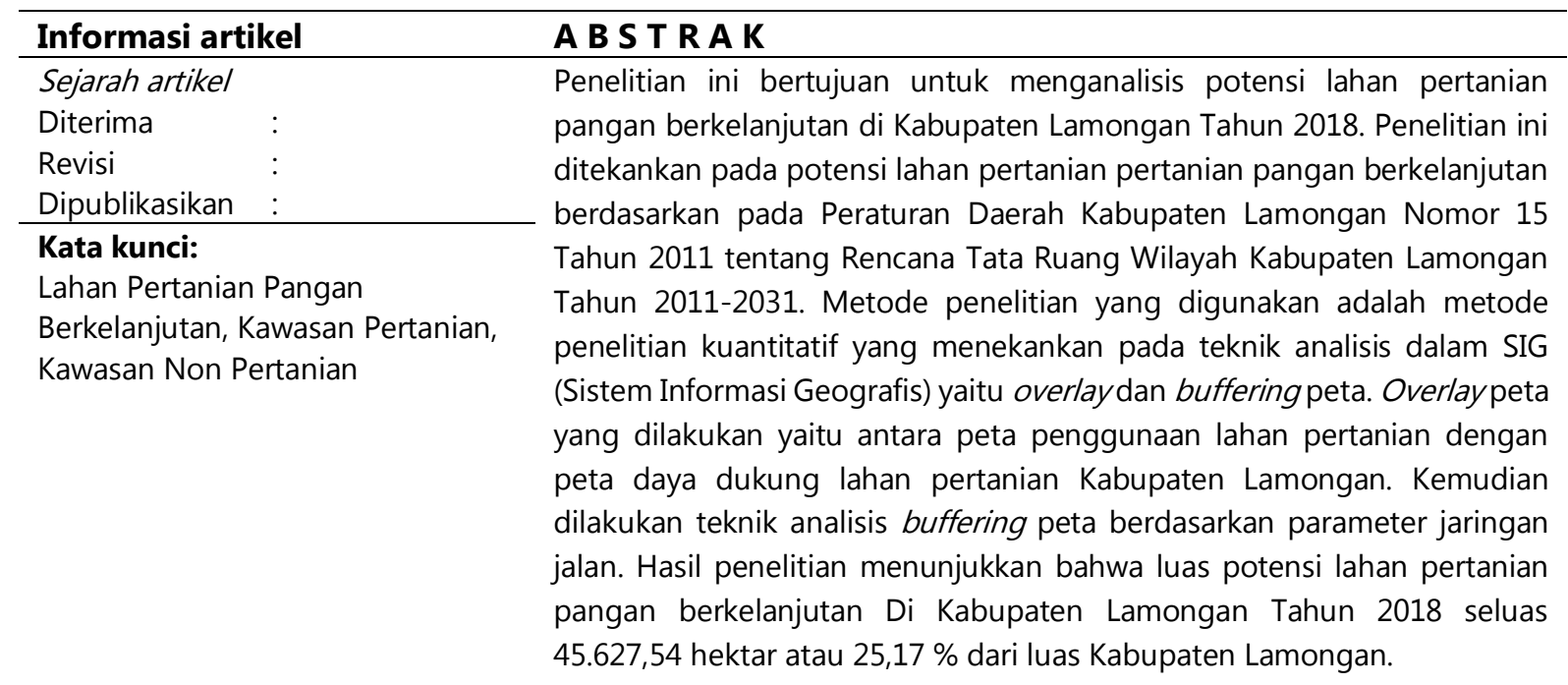

\section{Keywords:}

Sustainable food agricultural land, Agricultural Area, Non Agricultural Area

\begin{abstract}
A B S T R A C T
This study aims to analyze the potential of sustainable food agriculture land in Lamongan District in 2018. This research emphasizes the potential of sustainable food agriculture land based on Lamongan District Regulation Number 15 Year 2011 concerning Spatial Planning for Lamongan Regency in 2011-2031. The research method used is a quantitative research that emphasizes analytical techniques in GIS (Geographic Information Systems), namely overlay and buffering maps. Map overlay is done between the map of agricultural land use with a map of the carrying capacity agricultural land in Lamongan Regency. Then doing a map buffering analysis technique based on road network parameters. The results showed that the potential area for sustainable food agriculture in Lamongan Regency in 2018 was 45,627.54 hectares or $25.17 \%$ of the area of Lamongan Regency.
\end{abstract}

(C) 2019 (Mitha Asyita Rahmawaty). All Right Reserved

\section{Pendahuluan}

Indonesia merupakan negara agraris dengan sektor pertanian sebagai salah satu sektor unggulan yang dimiliki. Keberlanjutan sektor pertanian terutama pertanian tanaman pangan mendapat ancaman yang serius yaitu dengan mulai menyusutnya lahan-lahan pertanian di Indonesia akibat konversi lahan pertanian produktif ke penggunaan non-pertanian yang terjadi secara masif. Lahan-lahan pertanian lebih 
menguntungkan untuk dikonversikan menjadi perumahan, real estate, pabrik dan infrastruktur industri lainnya. Tingginya konversi lahan pertanian menjadi lahan non pertanian ini akan sangat berdampak serius dalam ketahanan pangan bangsa mengingat hampir semua penduduk di Indonesia mengkonsumsi beras sebagai makanan pokoknya (Widayati, 2015: 5-6). Selain itu, bertambahnya jumlah penduduk Indonesia yang cukup besar membuat kebutuhan akan pangan dari tahun ke tahun mengalami peningkatan. Sehubungan dengan jumlah penduduk Indonesia yang semakin meningkat maka kebutuhan akan ketersediaan pangan akan meningkat pula. Untuk itu ketersediaan pangan yang cukup mutlak diperlukan dengan ketersediaan lahan pertanian pangan yang mencukupi. Menurut data Badan Pusat Statistik Tahun 2018 diketahui bahwa telah terjadi penurunan luas baku lahan pertanian di Indonesia dari data sensus 2013 seluas 7,75 juta hektare menjadi 7,1 juta hektare pada 2018 (Purwanto, 2018). Untuk itu diperlukan perhatian khusus dalam mempertahankan lahan pertanian agar tidak beralih fungsi menjadi lahan-lahan non pertanian sehingga ketahanan pangan tetap terjaga. Menurut Peraturan Pemerintah Nomor 17 Tahun 2015 tentang Ketahanan Pangan dan Gizi menyatakan bahwa ketahanan pangan adalah kondisi terpenuhinya pangan bagi negara sampai dengan perseorangan, yang tercermin dari tersedianya Pangan yang cukup, baik jumlah maupun mutunya, aman, beragam, bergizi, merata, dan terjangkau serta tidak bertentangan dengan agama, keyakinan, dan budaya masyarakat, untuk dapat hidup sehat, aktif, dan produktif secara berkelanjutan. Fungsi ketahanan pangan ini penting untuk menjaga stabilitas negara akan ketercukupan pangan (Janti, 2016: 18-19).

Salah satu langkah yang diambil pemerintah Indonesia untuk mengatasi alih fungsi lahan pertanian menjadi lahan non pertanian dan mencukupi ketahanan pangan nasional adalah dengan penetapan lahan pertanian sebagai lahan pertanian pangan berkelanjutan (LP2B). Berdasarkan Undang-Undang No. 41 Tahun 2009 tentang Perlindungan Lahan Pertanian Pangan Berkelanjutan mendefinikan lahan pertanian pangan berkelanjutan (LP2B) adalah bidang lahan pertanian yang ditetapkan untuk dilindungi dan dikembangkan secara konsisten guna menghasilkan pangan pokok bagi kemandirian, ketahanan, dan kedaulatan pangan nasional. Sedangkan kegiatan perlindungan lahan pertanian pangan berkelanjutan adalah sistem dan proses dalam merencanakan dan menetapkan, mengembangkan, memanfaatkan dan membina, mengendalikan, dan mengawasi lahan pertanian pangan dan kawasannya secara berkelanjutan. Fungsi utama dari kegiatan perlindungan lahan pertanian pangan berkelanjutan adalah untuk melindungi dan menjamin tersedianya lahan pertanian secara berkelanjutan.

Berdasarkan Undang-Undang Nomor 26 tahun 2007 tentang Penataan Ruang mengamanatkan bahwa setiap daerah di Indonesia diharapkan dapat mengalokasikan lahan untuk pertanian pangan secara abadi melalui Peraturan Daerah Rencana Tata Ruang Wilayah (RTRW) sehingga keberlanjutan lahan pertanian pangan dapat tetap terjaga (Karenina, 2016: 2-3). Sakti et al. (2013: 56-57) mengemukakan bahwa dalam penyusunan Kawasan Pertanian Pangan Berkelanjutan wajib dilakukan oleh pemerintah baik mulai pemerintah kota kabupaten, pemerintah provinsi maupun pemerintah pusat sebagai upaya dalam memenuhi kebutuhan pangan untuk masyarakat Indonesia dan sebagai upaya untuk melindungi lahan-lahan pertanian subur yang memiliki produktivitas pertanian tinggi. Kawasan Pertanian Pangan Berkelanjutan yang diusahakan oleh Pemerintah Indonesia berada di Pulau Jawa. Pulau Jawa yang terdiri dari 6 (enam) provinsi memiliki luas lahan pertanian pangan yang besar dan menjadi pemasok pangan utama bagi penduduk Indonesia. Untuk itu perlu dilakukan kajian untuk mengetahui potensi lahan pertanian yang ada agar dapat ditetapkan sebagai lahan pertanian 
pangan berkelanjutan (LP2B) sehingga dapat melindungi lahan pertanian dan mencukupi kebutuhan pangan.

Salah satu kabupaten di Pulau Jawa yang memiliki potensi lahan pertanian yang cukup besar adalah Kabupaten Lamongan. Kabupaten Lamongan merupakan kabupaten yang berada di wilayah Provinsi Jawa Timur dengan luas wilayah kurang lebih $1.812,8 \mathrm{~km} 2$ atau $\pm 3,78 \%$ dari luas wilayah Provinsi Jawa Timur. Kabupaten Lamongan memiliki lahan khusus sawah saja seluas 87.318 hektar (BPS, 2018). Dengan lahan pertanian yang luas, Kabupaten Lamongan memiliki potensi yang besar dalam penetapan lahan pertanian pangan berkelanjutan. Akan tetapi dengan perkembangan wilayah Kabupaten Lamongan yang cukup pesat terutama dalam sektor industri (Mahaputra \& Santoso, 2018: 107108) menyebabkan alih fungsi lahan pertanian terutama sawah menjadi lahan non pertanian yaitu industri cukup masif. Perkembangan sektor industri menyebar hampir di setiap wilayah Kabupaten Lamongan (Azizah, 2014: 294-295). Hal ini memberikan kekhawatiran akan berkurangnya luas lahan pertanian akibat alih fungsi lahan menjadi lahan non pertanian.

Berdasarkan latar belakang tersebut maka perlu dilakukan penelitian untuk menganalisis potensi lahan pertanian yang dapat dijadikan lahan pertanian pangan berkelanjutan di Kabupaten Lamongan. Diharapkan dengan mengetahui potensi lahan pertanian pangan berkelanjutan maka dapat menjadi bahan dan masukan dalam menentukan kebijakan untuk melindungi dan menjamin tersedianya lahan pertanian di Kabupaten Lamongan. Tujuan dilakukan penelitian ini yaitu untuk menganalisis potensi lahan pertanian pangan berkelanjutan di Kabupaten Lamongan Tahun 2018.

\section{Metode}

Penelitian ini ditekankan pada potensi lahan pertanian pertanian pangan berkelanjutan berdasarkan pada Peraturan Daerah Kabupaten Lamongan Nomor 15 Tahun 2011 tentang
Rencana Tata Ruang Wilayah Kabupaten Lamongan Tahun 2011-2031.

Teknik pengumpulan data dalam penelitian ini dibagi menjadi 2 (dua), yaitu teknik pengumpulan data primer dan teknik pengumpulan data sekunder. Teknik pengumpulan data primer dilakukan dengan observasi lapangan sedangkan teknik pengumpulan data sekunder dilakukan dengan telaah dokumen. Telaah dokumen bersumber dari dokumen atau arsip yang terdapat dari instansi terkait terutama diambil dari Badan Perencanaan Pembangunan Daerah Kabupaten Lamongan, Dinas Tanaman Pangan, Holtikultura dan Perkebunan Kabupaten Lamongan serta Kantor Pertanahan Kabupaten Lamongan. Variabel yang digunakan pada penelitian ini, antara lain : jenis penggunaan lahan, luas tiap jenis penggunaan lahan, daya dukung lahan pertanian dan jaringan jalan.

Metode penelitian yang digunakan adalah metode penelitian kuantitatif. Metode penelitian kuantitatif ditekankan pada teknik analisis dalam SIG (Sistem Informasi Geografis) yaitu overlay dan buffering peta. Teknik analisis overlay peta adalah teknik dengan menempatkan grafis satu peta diatas grafis peta yang lain sedangkan teknik analisis buffering peta adalah teknik analisis yang menghasilkan data spasial baru yang berbentuk poligon berdasarkan jangkauan atau jarak tertentu dari data spasial yang kita inginkan. Overlay peta yang dilakukan yaitu antara peta penggunaan lahan pertanian Kabupaten Lamongan yang terdapat dalam Rencana Tata Ruang Wilayah Kabupaten Lamongan Tahun 2011 - 2031 dengan peta daya dukung lahan pertanian. Hasil dari teknik analisis overlay peta tersebut kemudian dilakukan teknik analisis buffering peta berdasarkan parameter jaringan jalan. Jaringan jalan dijadikan parameter karena berfungsi sebagai acuan dalam pengembangan wilayah non pertanian untuk masa yang akan datang. Zahnd (1999) mengemukakan bahwa dalam perkembangan horizontal suatu wilayah biasanya terjadi di lahan-lahan yang dekat dengan jalan 
raya. Berdasarkan uraian tersebut maka dibuat klasifikasi sempadan jaringan jalan untuk lahan pertanian berkelanjutan yang ditunjukkan oleh Tabel 1.

Tabel 1. Klasifikasi Sempadan Jaringan Jalan Untuk Lahan Pertanian Pangan Berkelanjutan

\begin{tabular}{llc}
\hline No & $\begin{array}{c}\text { Jenis Jaringan } \\
\text { Jalan }\end{array}$ & $\begin{array}{c}\text { Klasifikasi Sempadan } \\
\text { Jaringan Jalan (Meter) }\end{array}$ \\
\hline 1 & Jalan setapak & 5 \\
\hline 2 & $\begin{array}{l}\text { Jalan lokal dan } \\
\text { lingkungan }\end{array}$ & 10 \\
\hline 3 & Jalan kolektor & 500 \\
\hline 4 & Jalan arteri & 1000 \\
\hline
\end{tabular}

Berdasarkan teknik analisis SIG (Sistem Informasi Geografis) yaitu overlay dan buffering peta didapatkan hasil yaitu luas potensi lahan pertanian pangan berkelanjutan di Kabupaten Lamongan Tahun 2018.

\section{Hasil dan pembahasan}

Berdasarkan hasil peta penggunaan lahan Kabupaten Lamongan yang diperoleh dari Rencana Tata Ruang dan Wilayah Kabupaten Lamongan Tahun 2011-2031 menunjukkan bahwa penggunaan lahan di Kabupaten Lamongan pada tahun 2018 dibagi menjadi 2 kriteria yaitu kawasan pertanian dan kawasan non-pertanian. Kawasan pertanian yang terdiri dari sawah, ladang, dan perkebunan seluas $100.139,12$ ha. Sedangkan kawasan non pertanian terdiri dari pemukiman, industri, sungai, rawa, dan hutan seluas $81.140,88$ ha. Hal ini ditunjukkan oleh Tabel 2. dibawah ini.

Tabel 2. Luas Jenis Penggunaan Lahan Di Kabupaten Lamongan Tahun 2018

\begin{tabular}{clr}
\hline No & Jenis penggunaan lahan & \multicolumn{1}{c}{ Luas (ha) } \\
\hline 1. & Kawasan pertanian & $100.139,12$ \\
\hline 2. & Kawasan non pertanian & $81.140,88$ \\
\hline & Total & $\mathbf{1 8 1 . 2 8 0 , 0 0}$ \\
\hline
\end{tabular}

Berdasarkan Tabel 2. Luas Jenis Penggunaan Lahan Di Kabupaten Lamongan Tahun 2018 kemudian di lakukan analisis sehingga mendapatkan hasil bahwa kawasan pertanian sebesar $55 \%$ sedangkan kawasan non pertanian sebesar $45 \%$ dari total luas Kabupaten Lamongan seperti dijelaskan pada Gambar 1. dibawah ini.

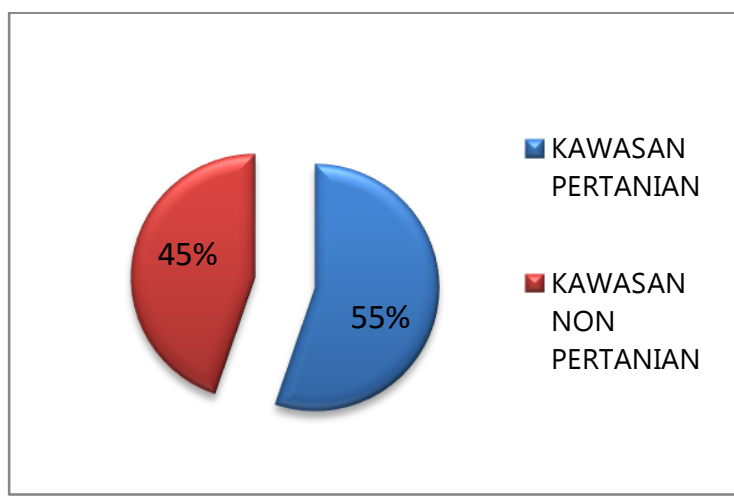

Grafik 1. Persentase Penggunaan Lahan Di Kabupaten Lamongan

Berdasarkan hal tersebut dapat dikatakan bahwa Kabupaten Lamongan merupakan Kabupaten yang memiliki potensi besar dalam sektor pertanian jika dilihat secara luas wilayah pertanian yang dimiliki. Adapun luas penggunaan lahan per kecamatan di Kabupaten Lamongan Tahun 2018 ditunjukkan pada Tabel 3 dibawah ini.

Tabel 3. Luas Penggunaan Lahan Per Kecamatan di Kabupaten Lamongan Tahun 2018

\begin{tabular}{clcc}
\hline No & Kecamatan & $\begin{array}{c}\text { Kawasan } \\
\text { pertanian } \\
\text { (ha) }\end{array}$ & $\begin{array}{c}\text { Kawasan } \\
\text { non } \\
\text { pertanian } \\
\text { (ha) }\end{array}$ \\
\hline 1. & Babat & $3.746,59$ & $2.548,41$ \\
\hline 2. & Bluluk & $3.065,97$ & $2.349,03$ \\
\hline 3. & Brondong & $1.558,19$ & $5.900,81$ \\
\hline 4. & Deket & $3.612,08$ & $1.392,92$ \\
\hline 5. & Glagah & $3.720,22$ & 331,78 \\
\hline 6. & Kalitengah & $3.116,59$ & $1.218,41$ \\
\hline 7. & Karangbinangun & $3.588,22$ & $1.699,78$ \\
\hline 8. & Karanggeneng & $2.929,97$ & $2.202,03$ \\
\hline 9. & Kedungpring & $4.597,28$ & $3.845,72$ \\
\hline 10. & Kembangbahu & $5.217,77$ & $1.166,23$ \\
\hline 11. & Lamongan & $1.150,92$ & $2.887,08$ \\
\hline 12. & Laren & $5.634,25$ & $3.965,75$ \\
\hline 13. & Maduran & $2.186,45$ & 828,55 \\
\hline 14. & Mantup & $5.615,55$ & $3.691,45$ \\
\hline 15. & Modo & $5.456,24$ & $2.323,76$ \\
\hline 16. & Ngimbang & $4.721,86$ & $6.711,14$ \\
\hline 17. & Paciran & $1.037,45$ & $3.751,55$ \\
\hline 18. & Pucuk & $2.901,34$ & $1.582,66$ \\
\hline
\end{tabular}




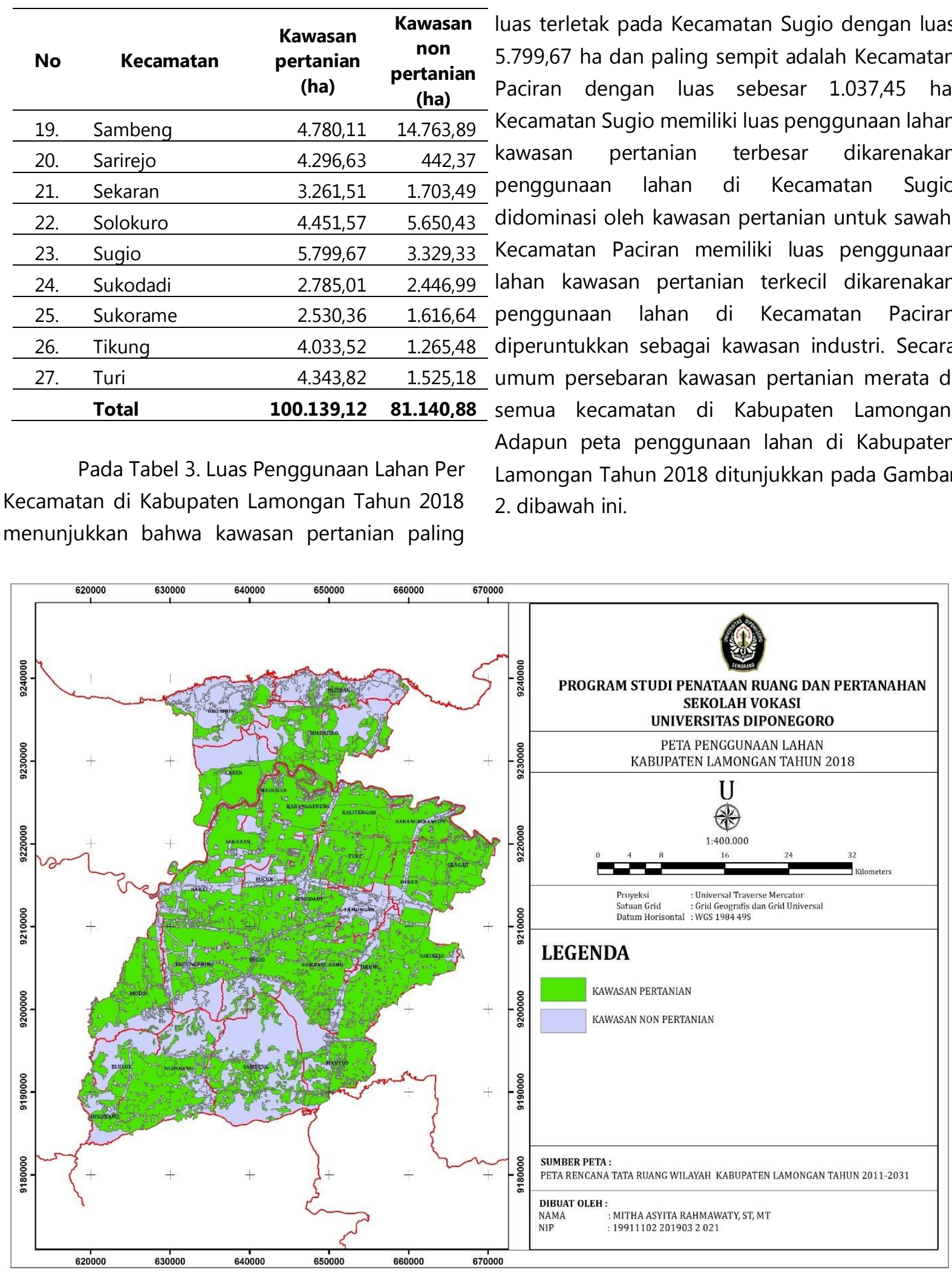

Gambar 2. Peta Penggunaan Lahan Kabupaten Lamongan Tahun 2018 
Rencana Pola Ruang Kabupaten Lamongan mengklasifikasikan daya dukung lahan pertanian Kabupaten Lamongan menjadi tiga kriteria, yaitu :
2) Daya Dukung Lahan Pertanian Sedang

3) Daya Dukung Lahan Pertanian Buruk

Gambar 3 berikut menunjukkan peta daya dukung lahan pertanian Kabupaten Lamongan.

1) Daya Dukung Lahan Pertanian Baik

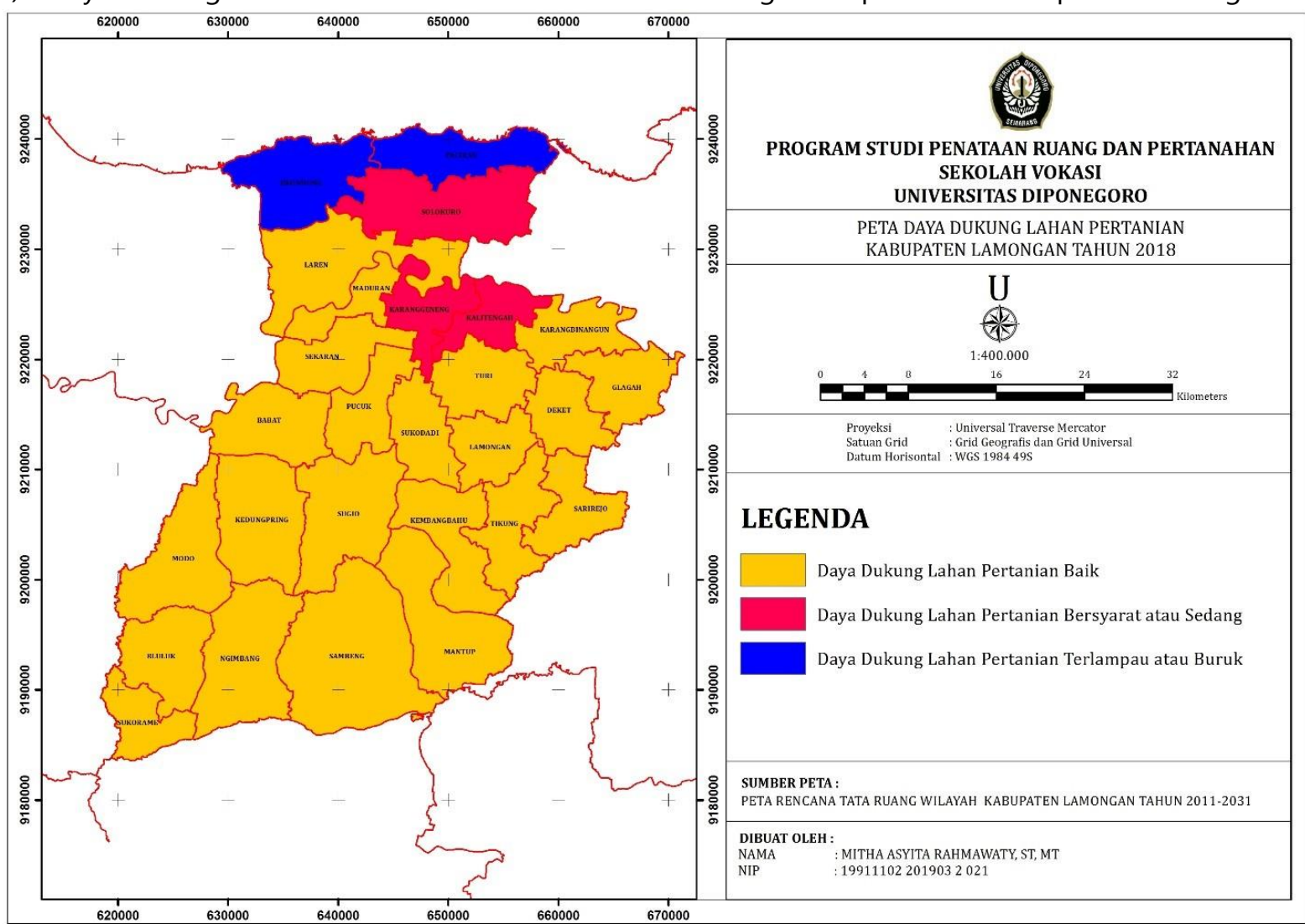

Gambar 3. Peta Daya Dukung Lahan Pertanian Kabupaten Lamongan Tahun 2018

Berdasarkan Gambar 3. Peta Daya Dukung Lahan Pertanian Kabupaten Lamongan 2018 diketahui bahwa kecamatan yang mempunyai daya dukung lahan pertanian buruk adalah Kecamatan Paciran dan Kecamatan Brondong. Hal ini dikarenakan kedua kecamatan tersebut merupakan peruntukan kawasan industri sehingga tidak sesuai untuk kegiatan pertanian. Kecamatan yang memiliki daya dukung lahan pertanian sedang adalah Kecamatan Solokuro, Kecamatan Karanggeneng, dan Kecamatan Kalitengah. Hal ini disebabkan karena ketiga kecamatan ini merupakan daerah rawan banjir dan jenis tanah merupakan tanah karst sehingga kurang sesuai untuk kawasan pertanian. Untuk kawasan pertanian yang memiliki daya dukung lahan pertanian baik adalah 23 kecamatan lain selain 4 kecamatan yang telah disebut, antara lain :
Kecamatan Babat, Kecamatan Bluluk, Kecamatan Deket, Kecamatan Glagah, Kecamatan Karangbinangun, Kecamatan Kedungpring, Kecamatan Kembangbahu, Kecamatan Lamongan, Kecamatan Laren, Kecamatan Mantup, Kecamatan Maduran, Kecamatan Modo, Kecamatan Ngimbang, Kecamatan Pucuk, Kecamatan Sambeng, Kecamatan Sarirejo, Kecamatan Sekaran, Kecamatan Sugio, Kecamatan Sukodadi, Kecamatan Sukorame, Kecamatan Tikung, dan Kecamatan Turi. Hal ini menunjukkan bahwa hampir semua wilayah kecamatan di Kabupaten Lamongan sangat sesuai untuk dijadikan kawasan pertanian dikarenakan mempunyai daya dukung lahan pertanian baik yang merata.

Gambar 4 berikut menunjukkan peta jaringan jalan Kabupaten Lamongan Tahun 2018. 


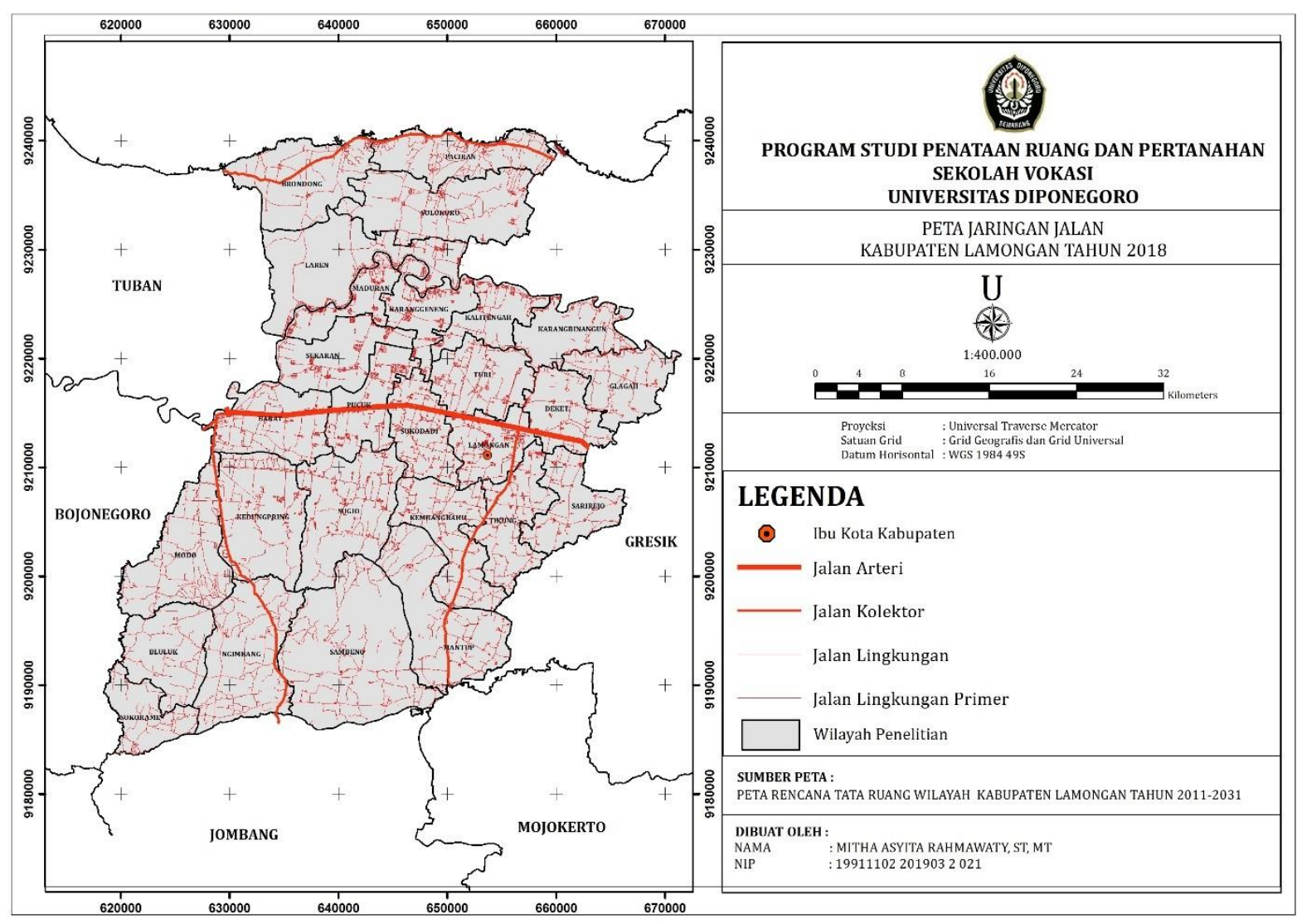

Gambar 4. Peta Jaringan Jalan Kabupaten Lamongan Tahun 2018

Berdasarkan Gambar 4. Peta Jaringan Jalan Kabupaten Lamongan 2018 diketahui bahwa Kabupaten Lamongan dilalui oleh Jalan Arteri (Jalan Nasional), Jalan Kolektor (Jalan Provinsi), Jalan Lingkungan (Jalan Kabupaten) dan Jalan Lain. Jalan arteri berada di tengah Kabupaten Lamongan. Jalan arteri ini merupakan Jalan Pantai Utara (PANTURA) Jawa yang memanjang dari Kecamatan Babat sampai dengan Kecamatan Deket. Jalan arteri ini membagi wilayah Kabupaten Lamongan menjadi 2 (dua) bagian yaitu bagian utara dan bagian selatan. Jalan kolektor berada di sebelah utara Kabupaten Lamongan yang menghubungkan Kabupaten Lamongan dengan Kabupaten Tuban dan Kabupaten Gresik. Jalan kolektor juga berada di sebelah selatan Kabupaten Lamongan yang menghubungkan Kabupaten Lamongan dengan Kabupaten Mojokerto dan Kabupaten Bojonegori dengan Kabupaten Jombang. Selain itu, terdapat jaringan jalan lingkungan yang menyebar diseluruh wilayah Kabupaten Lamongan berfungsi untuk menghubungkan kecamatan-kecamatan dan desa atau kelurahan di Kabupaten Lamongan.

Jaringan jalan menjadi parameter untuk memproyeksikan perkembangan kawasan non pertanian sebagai bagian dari tuntutan pertumbuhan wilayah. Selain itu pertumbuhan pemukiman biasanya terjadi disekitar jaringan jalan. Hal ini terkait dengan kemudahan aksesibilitas penduduk dalam melakukan aktivitasnya.

Berdasarkan hasil analisis potensi Lahan Pertanian Pangan Berkelanjutan (LP2B) Di Kabupaten Lamongan Tahun 2018 yang dilakukan dengan metode teknik analisis SIG (Sistem Informasi Geografis) yaitu overlay dan buffering peta didapatkan hasil bahwa luas potensi lahan pertanian pangan berkelanjutan Di Kabupaten Lamongan Tahun 2018 seluas 45.627,54 hektar atau 25,17 \% dari luas Kabupaten Lamongan. Hal ini menunjukkan bahwa kawasan pertanian di Kabupaten Lamongan sangat potensial untuk ditetapkan sebagai Lahan Pertanian Pangan Berkelanjutan (LP2B). Adapun hasil analisis 
potensi Lahan Pertanian Pangan Berkelanjutan (LP2B) per kecamatan di Kabupaten Lamongan Tahun 2018 ditunjukkan pada Tabel 4. dibawah ini.

Tabel 4. Potensi Lahan Pertanian Pangan Berkelanjutan (LP2B) Per Kecamatan Di Kabupaten Lamongan Tahun 2018

\begin{tabular}{|c|c|c|}
\hline No & Kecamatan & Potensi LP2B (Ha) \\
\hline 1. & Babat & $2.323,34$ \\
\hline 2. & Bluluk & 233,82 \\
\hline 3. & Brondong & 359,59 \\
\hline 4. & Deket & $1.457,92$ \\
\hline 5. & Glagah & $2.499,56$ \\
\hline 6. & Kalitengah & $2.474,84$ \\
\hline 7. & Karangbinangun & $2.856,29$ \\
\hline 8. & Karanggeneng & $2.214,93$ \\
\hline 9. & Kedungpring & $3.084,27$ \\
\hline 10. & Kembangbahu & 926,44 \\
\hline 11. & Lamongan & 666,73 \\
\hline 12. & Laren & $3.403,12$ \\
\hline 13. & Maduran & $1.933,78$ \\
\hline 14. & Mantup & $1.071,65$ \\
\hline 15. & Modo & $2.057,46$ \\
\hline 16. & Ngimbang & 739,97 \\
\hline 17. & Paciran & 220,64 \\
\hline 18. & Pucuk & $2.039,21$ \\
\hline 19. & Sambeng & 844,53 \\
\hline 20. & Sarirejo & 889,74 \\
\hline 21. & Sekaran & $2.938,31$ \\
\hline 22. & Solokuro & 924,35 \\
\hline 23. & Sugio & $4.520,61$ \\
\hline 24. & Sukodadi & $1.847,64$ \\
\hline 25. & Sukorame & 234,71 \\
\hline 26. & Tikung & 572,29 \\
\hline 27. & Turi & $2.291,80$ \\
\hline \multicolumn{2}{|r|}{ Total } & $45.627,54$ \\
\hline
\end{tabular}

Berdasarkan Tabel 4. Potensi Lahan Pertanian Pangan Berkelanjutan (LP2B) Per Kecamatan Di Kabupaten Lamongan Tahun 2018 diketahui bahwa kecamatan dengan luas potensi Lahan Pertanian Pangan Berkelanjutan (LP2B) terbesar adalah Kecamatan Sugio dengan luas
4.520,61 hektar. Hal ini dikarenakan Kecamatan Sugio merupakan kecamatan dengan luas kawasan pertanian terbesar di Kabupaten Lamongan dan memiliki daya dukung lahan pertanian yang baik. Selain itu, Kecamatan Sugio tidak dilewati baik oleh jalan arteri maupun jalan kolektor sehingga potensi untuk keberlanjutan kawasan pertaniannya dapat terjaga dikarenakan perkembangan kawasan non pertaniannya tidak pesat. Untuk kecamatan dengan luas potensi Lahan Pertanian Pangan Berkelanjutan (LP2B) terkecil adalah Kecamatan Paciran dengan luas 220,64 hektar. Hal ini dikarenakan berdasarkan Rencana Tata Ruang Wilayah (RTRW) Kabupaten Lamongan Tahun 2011-2031, Kecamatan Paciran diperuntukan sebagai kawasan industri sehingga tidak sesuai untuk dijadikan kawasan pertanian. Selain itu, Kecamatan Paciran memiliki luas kawasan pertanian terkecil di Kabupaten Lamongan dengan daya dukung lahan pertanian yang buruk. Kecamatan Paciran juga dilewati oleh jalan kolektor yang ramai untuk menunjang kawasan industri sehingga Kecamatan Paciran mengalami perkembangan wilayah yang pesat. Perkembangan wilayah Kecamatan Paciran yang pesat berdampak pada terjadinya alih fungsi lahan pertanian ke lahan non pertanian yang terjadi disepanjang jalan kolektor secara masif.

Secara umum potensi Lahan Pertanian Pangan Berkelanjutan (LP2B) menyebar disemua kecamatan Kabupaten Lamongan. Hal tersebut menunjukkan bahwa setiap wilayah kecamatan di Kabupaten Lamongan memiliki kawasan pertanian yang berpotensi besar untuk ditetapkan sebagai Lahan Pertanian Pangan Berkelanjutan (LP2B). Untuk itu diperlukan kebijakan khusus dalam melindungi dan menjaga kawasan pertanian ini agar tidak beralih fungsi menjadi kawasan non pertanian akibat dari perkembangan wilayah di Kabupaten Lamongan. Adapun peta analisis potensi Lahan Pertanian Pangan Berkelanjutan (LP2B) di Kabupaten Lamongan Tahun 2018 ditunjukkan pada Gambar 5. dibawah ini. 


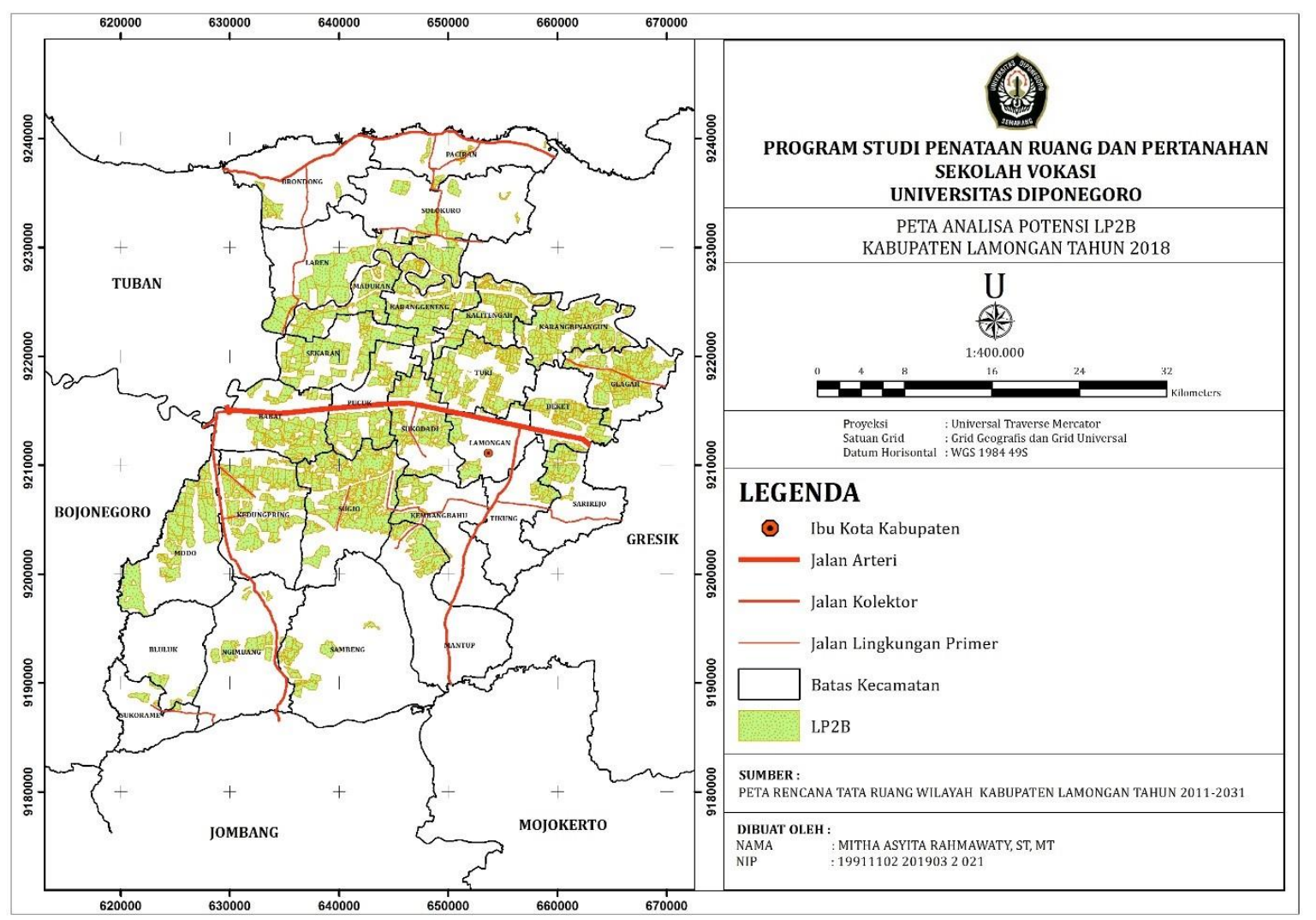

Gambar 5. Peta Analisis Potensi Lahan Pertanian Pangan Berkelanjutan (LP2B) di Kabupaten Lamongan Tahun 2018

\section{Simpulan}

Berdasarkan hasil analisis dapat disimpulkan bahwa luas potensi lahan pertanian pangan berkelanjutan Di Kabupaten Lamongan Tahun 2018 seluas 45.627,54 hektar atau 25,17\% dari luas Kabupaten Lamongan. Kecamatan dengan luas potensi lahan pertanian pangan berkelanjutan terbesar adalah Kecamatan Sugio dengan luas 4.520,61 hektar sedangkan Kecamatan dengan luas potensi lahan pertanian pangan berkelanjutan terkecil adalah Kecamatan Paciran dengan luas 220,64 hektar. Diharapkan dengan penelitian ini kedepannya dapat menjadi salah satu instrumen yang dapat membantu untuk memonitor situasi ketahanan pangan wilayah di Kabupaten Lamongan. Hal ini juga mendukung FAO (Food and Agriculture Organization of the United Nations) dalam melaksanakan salah satu programnya di SDGs yaitu Sustainable Food and Agriculture yang ditargetkan selesai pada tahun 2030.

\section{Ucapan terima kasih}

Ucapan terima kasih disampaikan kepada berbagai pihak yang telah membantu dalam penelitian/penyusunan artikel.

\section{Referensi}

Azizah, N. (2014). Model pengembangan industri kecil konveksi melalui apik (asosiasi pengrajin industri konveksi) di Desa Tritunggal Kecamatan Babat Kabupaten Lamongan Jawa Timur. Economics Development Analysis Journat. 293-306.

Purwanto, D.. (2019, 30 Oktober). Luas Lahan Pertanian RI Menyusut. Diakses pada 5 November 2019, dari http://www.harnas.co/2018/10/29/luaslahan-pertanian-ri-menyusut. 
Janti, G. I. (2016). Perlindungan lahan pertanian pangan berkelanjutan guna memperkokoh ketahanan pangan wilayah (Studi di Kabupaten Bantul, Daerah Istimewa Yogyakarta). Jurnal Ketahanan Nasional 22(1): 1-21.

BPS Kabupaten Lamongan. (2018). Kabupaten Lamongan Dalam Angka 2018. Badan Pusat Statistik: Kabupaten Lamongan

Karenina, A. (2016). Strategi perlindungan lahan pertanian pangan berkelanjutan di Kabupaten Tangerang. Jurnal Manajemen Pembangunan Daerah 8(2): 1-9.

Mahaputra, G. P., \& Santoso, E. B. (2018). Arahan Pengembangan Kawasan Industri Maritim di Wilayah Brondong-Paciran, Kabupaten Lamongan. JURNAL TEKNIK ITS 7(2): 107-112.

Pemerintah Republik Indonesia. (2015). Peraturan Pemerintah Nomor 17 Tahun 2015 tentang Ketahanan Pangan dan Gizi

Pemerintah Kabupaten Lamongan. (2011). Peraturan Daerah Kabupaten Lamongan Nomor 15 Tahun 2011 tentang Rencana Tata Ruang Wilayah Kabupaten Lamongan Tahun 2011-2031

Sakti, et al. (2013). Kajian pemetaan lahan pertanian pangan berkelanjutan (LP2B) di kabupaten purworejo. Jurnal ilmu tanah dan Agroklimatologi: 55-70.

Pemerintah Republik Indonesia. (2009). UndangUndang No. 41 Tahun 2009 tentang Perlindungan Lahan Pertanian Pangan Berkelanjutan

Widayati, W. (2015). Kebijakan perlindungan lahan pertanian pangan berkelanjutan di Kabupaten Demak. Jurnal IImiah IImu Pemerintahan 1(1): 5-11.

Zahnd, M.. (1999). Perancangan Kota Secara Terpadu. Penerbit Kanisius: Yogyakarta. 